\title{
Eco-Friendly Alternatives for Storage Pest Management:Leaves of Ruta Graveolens (Aruda) as a Repellent Against the Rice Weevil, Sitophilus Oryzae L.
}

\author{
A. G. W. U. Perera and M. M. S. C. Karunaratne \\ Department of Zoology, University of Sri Jayewardenepura, Nugegoda, Sri Lanka
}

\begin{abstract}
In view of worldwide interest and greater public awareness in finding plant products as the most promising and ecologically safer alternatives for synthetic insecticides in post-harvest protection of stored rice, present study was undertaken to explore the potential of leaves of Ruta graveolens (Aruda) as a repellent against S.oryzae infestations. Leaf powder and solvent extracts of $R$. graveolens were evaluated for their contact and fumigant repellent properties against seven day old S. oryzae adults. In contact repellency test, weevils (20 each) were exposed to $1.0 \mathrm{~g}, 3.0 \mathrm{~g}, 5.0 \mathrm{~g}$, and $7.0 \mathrm{~g}$ of leaf powder mixed with white raw rice grains in a modified cup bioassay apparatus. Fumigation repellency of leaf powder was tested using same dosages and the number of weevils in a fumigation-repellency chamber. Number of weevils that moved from the bioassay chamber was recorded one hour after weevil introduction. Leaves of $R$. graveolens were extracted in hexane, ethyl acetate, methanol, distilled water and different concentrations 10, 50, 100\% (v/v) were assessed separately to evaluate repellent activity by means of an area preference bioassay. In all experiments, ten weevils for each were tested and the number repelled was recorded 30 minutes after weevil introduction. Highest contact and fumigant repellent effects were elicited by $7.0 \mathrm{~g}$ of leaf powder resulting $96 \%$ and $95 \%$ respectively, whilst lowest dose also produced more than 50\% repellency indicating extremely strong repellent action of the plant powder. In comparison, aqueous extract exhibited the most potent repellent activity (91\%) while other extracts were producing over $70 \%$ repellent effects on weevils at the concentration of $100 \%(v / v)$. Overall findings of the study suggest that both powder and extracts of $R$. graveolens leaves could be used as eco-friendly agents for post-harvest rice protection.
\end{abstract}

KEYWORDS: Ruta graveolens, Sitophilus oryzae, stored rice, leaf powder, repellent

Corresponding author: A. G. W. U. Perera, Email: wathsalauda@gmail.com 


\section{INTRODUCTION}

The Sri Lankan economy is primarily based on agriculture. Among many food crops cultivated, rice constitutes the main crop in Sri Lanka and the staple food of Sri Lankans which is more importantly the livelihood of more than 800,000 farm families (Dharmasena \& Abeysiriwardena, 2003).

In spite of the growth of paddy production, considerable losses are reported to occur throughout the production process, and post harvest losses account for $15 \%$ of the total loss (Palipane, 2000). The most significant loss in the post harvest operations occurs during storage of paddy and rice, and is caused by improper and inadequate facilities, particularly at farm level (Adhikarinayake, 2005). Recent studies have revealed that grain loss during storage under normal ware-house conditions due to various agents of grain deterioration is $4-6 \%$ and $80 \%$ of this loss is due to insect attack (Palipane, 2001). Rice weevil (Sitophilus oryzae), grain moth (Sitotroga cerealella), and red flour beetle (Tribolium casteneum) are three devastating insect pests of stored paddy and rice in Sri Lanka (Wijayaratne et al., 2009). Among them, rice weevil (Sitophilus oryzae) is considered as the major stored pest of paddy and rice all over the world (Suvanthni et al., 2012).

Since 1950s, synthetic insecticides have been used extensively in grain facilities because of their effectiveness and easy application to control stored insect pests (Rajashekar et al., 2012). The direct application of an insecticide to a food commodity will always produce a residue which will be more or less persistent depending on the chemical nature of the insecticide used. This may however create a potential hazard or, at least, a source of possible anxiety to the user of the commodity (FAO, 1999).

However, the indiscriminate, regular and routine use of synthetic insecticides has some serious drawbacks such as development of resistance strains, resurgence, frequent pest outbreaks, environmental problems, ecological imbalance, and health hazards (Rahman et al., 2003). Higher public awareness of these risks, precautions essential in dealing with traditional chemical insecticides (Fields et al., 2001) and the poor storage facilities of traditional farmers which are unsuitable for effective conventional chemical control (Tapondjou et al., 2002, Moreira et al., 2007) increase the interest in finding safer and alternative stored product protectants for insect pest control.

Higher plants are a rich source of unique insecticides (Dev \& Koul, 1997) and have been used for hundreds of years, but were displaced from the market by synthetic insecticides. Those plants and plant derived products deserve consideration for use in stored insect pest control because they are convenient to use and environmentally safe (Singh et al., 2010). The use of plants in the protection of stored grains against insect infestation has been an age-old practice among small-scale farmers in Sri Lanka (Palipane, 2000). Scientific evaluation and full documentation of plants for insect pest management purposes is still lacking, though medicinal plant research has gained more consideration (Chikukura et al., 2011).

Hence the present study has been undertaken to explore the repellent potential of the leaves of Ruta graveolens to suppress Sitophilus oryzae infestations in the view of worldwide interest and greater public awareness in finding plant products for the replacement of synthetic insecticides in the post harvest protection of stored rice and paddy.

\section{BACKGROUND}

The control of rice weevil infestations has been primarily through the use of fumigants and residual chemical insecticides to augment the more obvious approach of hygiene. Treatment of rice with those synthetic insecticides is not recommended as the rice is meant for human consumption because of direct and indirect health hazards (Bello et al., 2001). Greater 
public awareness of these risks has increased worldwide interest in finding safer insecticides or alternative stored product protectants to replace conventional insecticides and fumigants (Paranagama et al., 2003).

Different types of plant preparations such as powders, solvent extracts and whole plants are being investigated for their insecticidal activity including their action as fumigants, repellents, anti-feedants, anti-ovipositions and insect growth regulators (Khoshnoud et al., 2008). The use of plants in the protection of stored grains against insect infestation has been as age-old practice among small-scale farmers in Sri Lanka. Plant leaves of Ocsimum sancturm (Maduruthala), Azadirichta indica (Neem), Citrus spp., Vitex negando (Nika), Curcuma longa (Amukaha), Eucaliptus terreticornis have been used at $1 \%$ dose rate for insect control in storage of grains (Palipane, 2000).

Therefore the scientific community at international level is looking for the development of safer, cost effective and environmentally friendly alternative products from plants for effective control of insect pests during storage (Tripathi et al., 2008).

\section{MATERIALS AND METHODS}

\subsection{Plant Material}

Fresh, mature and healthy leaves of Ruta graveolens (Aruda) were collected from Bandarawela region. These were washed, air dried and ground into a fine powder using a domestic electric grinder (Multinational ${ }^{\circledR}, 2101$, India). Then the powder was packed in glass containers with tight lids and stored in a refrigerator at $4^{0} \mathrm{C}$ prior to use.

\subsection{Insect Cultures}

Sitophilus oryzae used for the study were obtained from infested stock of rice in local market and then reared on wholly, un-infested rice grains in glass jars covered with muslin cloth held in place with rubber bands for the passage of air at $29 \pm 2{ }^{\circ} \mathrm{C}$ and $84 \pm 2 \%$ relative humidity. One week old adult rice weevils were used for all experiments.

\subsection{Preparation and Extraction of Plant Material}

Sixty grams of dried powders of Ruta graveolens (Aruda) were extracted sequentially with the solvents of Methanol (99.85\%) and distilled water using soxhlet apparatus (Shanti Scientific Industries, India) in three consecutive terms. The extraction was preceded up to 18 hours at $62^{\circ} \mathrm{C}$. Methanol extract of Ruta graveolens (Aruda) was further partitioned between n-Hexane (95\%) and Ethyl Acetate $(99.5 \%)$. The resulting extracts were then subjected to solvent evaporation at $65^{\circ} \mathrm{C}$ using rotary evaporator (Microsil, India) until they were reduced approximately to $50 \mathrm{ml}$ and were subsequently stored in the refrigerator at $4^{\circ} \mathrm{C}$. These final products were then re-dissolved in respective solvent to obtain required dilutions of 10,50 and $100 \%(\mathrm{v} / \mathrm{v})$ in each plant extract for experimental use.

\subsection{Contact Repellent Effect of Leaf Powders}

Contact repellency was tested according to the standard method adopted by Mohan and Fields (2002) with some modifications. Portions of 1.0, $3.0,5.0$ and $7.0 \mathrm{~g}$ of leaf powders of Ruta graveolens corresponding to 3.33, 10.00, 16.67 and $23.33 \%(\mathrm{w} / \mathrm{w})$ concentrations were weighed and each added into a small plastic cup (height 8 $\mathrm{cm}$, diameter $7.5 \mathrm{~cm}$ ) which contained $30 \mathrm{~g}$ of clean, undamaged and uninfested rice grains. The grains in the controls contained no leaf powders. The top $1 / 4$ height of the small plastic cup was perforated using a soldering gun (220V/240V, 40W, China). Those holes were made to allow the weevils to escape from the plastic cup if they are repelled by the leaf powders. This small plastic cup was then placed inside a large plastic bottle (height $15 \mathrm{~cm}$, diameter $7.5 \mathrm{~cm}$ ) to trap the weevils that are moving out through the holes of the small plastic 
cup. One week old, 20 adult weevils were introduced into each small plastic cup. Before onset of each experiment, holes were covered for 10 minutes to let the introduced rice weevils settle down inside the plastic cup. The bioapparatus was then covered with muslin cloth held in place with rubber bands to allow the air passage for weevils. The number of repelled weevils in the large plastic bottle was counted one hour after their introduction to calculate rice weevil repellency. The experiment was replicated five times.

\subsection{Fumigation Repellent Effect of Leaf Powders}

The bio apparatus used was somewhat similar to the setup in the contact repellency bioassay but with some alterations (Mohan \& Fields, 2002). The bottom of the small plastic cup was removed and replaced by a nylon cloth which was then fitted with a small plastic container (height $4 \mathrm{~cm}$, diameter $5 \mathrm{~cm}$ ) to place the leaf powders inside the latter. This adjustment allowed the vapour of leaf powders inside the container to pass through the cloth and reach the weevils. Leaf powder was then put in the plastic container, and $30 \mathrm{~g}$ of clean and uninfested rice grains were placed in the small plastic cups. One week old, 20 adult weevils were introduced into the small plastic cups. $1.0,3.0,5.0$ and $7.0 \mathrm{~g}$ of leaf powders were tested separately. The grains in the control test contained no leaf powders. Number of repelled weevils in the large plastic bottle was counted one hour after introduction. The experiment was replicated five times.

\subsection{Repellent Effect of Leaf Extracts}

The repellent effect was evaluated using the area preference bioassay adopted after McDonald (1970), Talukder and Howse (1993) with some modifications. The test area consisted of a Filtermann ${ }^{\circledR}(125 \mathrm{~mm})$ paper that was cut into 2 halves. One half of the filter paper was treated with $1 \mathrm{ml}$ of each prepared concentration $(10,50$ and $100 \%(\mathrm{v} / \mathrm{v}))$ of respective leaf extracts (Methanol, n-Hexane, Ethyl acetate, water) as uniformly as possible. The other half (control) was treated only with $1 \mathrm{ml}$ of the respective solvent. Both the treated and control halves were then air dried to evaporate the solvent completely. A full disc was carefully remade by attaching the treated half the control half lengthwise, edge-to-edge with adhesive paper tape. Each remade filter paper was then placed in a petri dish and $10 \mathrm{~g}$ of clean and uninfested rice grains was uniformly distributed over it as an attractant for the rice weevils. One week old, 10 adult rice weevils were released in the center of each filter paper disc and cover was placed over the petri dish. For each leaf extract and each concentration, 10 replicates were made. The number of weevils present on each half was counted 30 minutes after the introduction of rice weevils.

\subsection{ANALYSIS OF DATA}

All data obtained for repellency bioassays were subjected to one-way analysis of variance (ANOVA) using Minitab 14.0. Tukey's multiple comparison test was used to separate mean values of the experiments, where significant differences existed $(\mathrm{p} \leq 0.05)$. Comparisons between concentrations of leaf extracts were analyzed using the General Linear Model (GLM).

\section{RESULTS AND DISCUSSION}

The repellent effect of leaf powders of $R$. graveolens on rice weevils after an hour of exposure in the contact and fumigation repellency bioassays are shown in the in Table 1. According to the results, it was evident that all the doses elicited significantly higher repellent actions after an hour from the weevil exposure when the leaf powders were used in both contact and vapor forms in comparison to the control which gave no repellency at all. The contact and fumigation repellent effect of $R$. graveolens leaf powders progressively increased with the increase in dose. $R$. graveolens manifested strong contact and fumigant repellent actions accounting to $96.00 \pm 3.18$ and $95.00 \pm 3.54$ 
respectively. Even the lowest dose of $1 \mathrm{~g}$ was able to produce over $50 \%$ fumigation repellent activity within an hour thus indicating the strong effectiveness of $R$. graveolens leaf powders as fumigants.

Table 1. Repellent effect of leaf powders of Ruta graveolens on S. oryzae after 1 hour in the contact and fumigation repellency bioassays

\begin{tabular}{|c|c|c|}
\hline \multirow{2}{*}{$\begin{array}{c}\text { Dose } \\
(\mathbf{g})\end{array}$} & \multicolumn{2}{|c|}{$*$ Mean \% Repellency \pm SD } \\
\cline { 2 - 3 } & $\begin{array}{c}\text { Contact } \\
\text { Repellency }\end{array}$ & $\begin{array}{c}\text { Fumigation } \\
\text { Repellency }\end{array}$ \\
\hline Control & $0.00 \pm 0.00^{\mathrm{a}}$ & $0.00 \pm 0.00^{\mathrm{a}}$ \\
\hline $\mathbf{1}$ & $69.00 \pm 4.18^{\mathrm{b}}$ & $58.00 \pm 2.74^{\mathrm{b}}$ \\
\hline $\mathbf{3}$ & $85.00 \pm 5.00^{\mathrm{c}}$ & $79.00 \pm 4.18^{\mathrm{c}}$ \\
\hline $\mathbf{5}$ & $93.00 \pm 2.73^{\mathrm{cd}}$ & $90.00 \pm 3.54^{\mathrm{d}}$ \\
\hline $\mathbf{7}$ & $96.00 \pm 3.18^{\mathrm{d}}$ & $95.00 \pm 3.54^{\mathrm{d}}$ \\
\hline
\end{tabular}

* Means followed by the same letters within the columns are not significantly different (Tukey's test at $\mathrm{p}<0.05$ )

*Mean Percentage Repellency \pm SD for five replicates $(\mathrm{n}=100)$

Data on the effectiveness of $R$. graveolens leaf extracts on $S$. oryzae adults (Table 2) showed that all the extracts elicited weevil repellency which ranged between $72 \%$ - 91\% within 30 minutes after exposure at the highest concentration tested.

Table 2. Percentage repellency for the leaf extracts of $R$. graveolens on Sitophilus oryzae after 30 minutes of exposure in the area preference bioassay

\begin{tabular}{|c|c|c|c|c|}
\hline \multirow{4}{*}{ Dose } & \multicolumn{4}{|c|}{ *Mean \% Repellency \pm SD } \\
\cline { 2 - 5 } & Hexane & $\begin{array}{c}\text { Ethyl } \\
\text { Acetate }\end{array}$ & Methanol & Water \\
\hline \multirow{2}{*}{ T1 } & $63.00 \pm$ & $65.00 \pm$ & $74.00 \pm$ & $80.00 \pm$ \\
& $6.75^{\mathrm{a}}$ & $9.72^{\mathrm{a}}$ & $8.43^{\mathrm{a}}$ & $8.17^{\mathrm{a}}$ \\
\hline \multirow{2}{*}{ T2 } & $66.00 \pm$ & $74.00 \pm$ & $83.00 \pm$ & $85.00 \pm$ \\
& $5.16^{\mathrm{a}}$ & $9.67^{\mathrm{a}}$ & $6.75^{\mathrm{ab}}$ & $5.27^{\mathrm{a}}$ \\
\hline \multirow{2}{*}{ T3 } & $72.00 \pm$ & $79.00 \pm$ & $84.00 \pm$ & $91.00 \pm$ \\
& $7.89^{\mathrm{a}}$ & $8.76^{\mathrm{a}}$ & $8.43^{\mathrm{b}}$ & $8.76^{\mathrm{a}}$ \\
\hline
\end{tabular}

* Means followed by the same letters within the columns are not significantly different according to the Tukey's test at $\mathrm{P}<0.05$
*Mean Percentage Repellency \pm SD for ten replicates $(\mathrm{n}=100)$

T1- 10\%v/v; T2- 50\%v/v; T3 - 100\%v/v

Over $60 \%$ repellent action was noticed at the lowest concentrations for all the extracts within the same time period after treatment. The aqueous leaf extract was found to be the most effective causing 91\% repellency followed by methanol and ethyl acetate based leaf extracts whereas hexane based leaf extract was the least effective $(72 \%)$ indicating the lower level of repellency. It is noteworthy that repellent rate of the leaf extracts were increased with the increase in the concentrations.

Plant products notably in the form of leaf powders and leaf extracts having considerable potential in repelling ubiquitous stored grain insect pests are gaining tremendous importance in the insect pest management programs around the world. Ruta graveolens which has been used as the key plant in the present investigation is a perennial semi-shrubby plant cultivated in upcountry of Sri Lanka (Jayaweera, 1982; Kirtikar $\&$ Basu, 1987). It is given internally for hysteria, amenorrhoea epilepsy and flatulent colic while it is used externally as a rubefacient (Jayaweera, 1982; Warier et al., 1996). Leaves are used in cases of rheumatalgia (Dassanayake \& Fosberg, 1985). It is reported that herbal tea made with ruta leaves reduces high blood pressure and sciatica. Also, it was known practice in Sri Lanka to use ruta leaves for infantile catarrh (Fernando, 1982). In Central Province of Sri Lanka, the leaves pounded with salt and are applied locally for scorpion sting (Kirtikar \& Basu, 1987). The bitter leaves of $R$. graveolens are a traditional seasoning in Mediterranean countries where it is used to flavor meats, fish, salads, and egg and cheese dishes. In Africa, especially in Ethiopia, fresh leaves are used to flavor coffee (Harsha \& Latha, 2012).

Since there is no published material on using $R$. graveolens leaf powders in the suppression of stored product insect pests, this study represents the first record of their repellent potential in controlling Sitophilus oryzae infestations. The 
findings of the present study explicitly showed that the leaf powders of $R$. graveolens have extremely high potential in protecting rice from rice weevils with their great contact and fumigation repellent activities within an hour. With regard to extracts of the leaves of $R$. graveolens (Hexane, Ethyl Acetate, Methanol and aqueous), aqueous extract exhibited very strong repellent activity whereas that hexane extract elicited comparatively lesser repellent activity against rice weevils. Only a few bibliographical data are available on the potential of $R$. graveolens leaf extracts on different insect species and also in contrast, data of its repellent properties against $S$. oryzae are ambiguous. Rojht et al. (2012) revealed that, ethanol based leaf extract of $R$. graveolens was highly repellent against bean weevils (Acanthoscelides obtectus). A study conducted by Potenza et al. (2006) evaluated the mortality of aqueous and acetone leaf extracts of $R$. graveolens against the maize weevil (Sitophilus zeamais). However, the varying activity elicited by different leaf extracts of $R$. graveolens indicates that the chemical compounds involved in repellent effect against rice weevils exerted by each extract may not be uniformly present in the plant (Rahman et al., 2007). Therefore the repellent activity of the leaf extracts is probably due to the number of secondary metabolites pulled up by each extract by itself in accordance with the respective polarity of the extracts or the great effectiveness exerted by the major constituents sporadically. However biological activity of leaf extracts is generally attributed to some particular compounds, a synergistic phenomenon among these metabolites may result in a higher biological activity compared to the isolated components according to Berenbaum, 1985; Hummelbrunner \& Isman, 2001and Neiro et al., 2010. It has been suggested that this occurs due to the fact that plants usually present defenses as a suite of compounds, not as individual ones enhancing the effectiveness of the major constituents through a variety of mechanisms (Berenbaum, 1985; Neiro et al., 2010).

\section{CONCLUSION}

The present investigation has brought out the great contact and fumigation repellent efficacies of both leaf powders and the leaf extracts of $R$. graveolens in providing grain protection and may be exploited for rice weevil control in an environmental-friendly way. Therefore, the leaves of Ruta graveolens may be recommended as cheap, easily available at farmer level and non-toxic agents and can be utilized as a very successful candidate in the development of bioinsecticides in controlling Sitophilus oryzae infestations. Further studies are required to find out the repellent potential of the leaves of $R$. graveolens on other stored insect pests as well. Since the leaves of $R$. graveolens are opulent with the fumigant activities, it would be worthwhile extending the study further to identify the specific volatile components which are effective against Sitophilus oryzae infestations. It is likely that detailed studies on the structure and mode of action of the biologically active volatile compounds would open up the path for the commercialization of such volatiles in future.

\section{ACKNOWLEDGMENT}

We express our gratitude to the Department of Zoology, Faculty of Applied Sciences, University of Sri Jayewardenepura, Sri Lanka, for providing necessary facilities during research

\section{REFERENCES}

ADHIKARINAYAKE TB. Methodical Design Process to Improve Income of Paddy Farmers in Sri Lanka. Ph D. The Netherlands: Wageningen University; 2005.

BELLO GD, PADIN S, LASTRA CL \& FABRIZIO M. Laboratory evaluation of chemical-biological control of the rice weevil (Sitophilus oryzae L.) in stored grains. Jounal of Stored Products Research. 2001; 37: 77-84. 
BERENBAUM M. Allelochemical interactions in plants. Recent Advances in Phytochemistry. 1985; 19:139-169.

CHIKUKURA L, MVUMI BM, CHIKONZO R \& CHENZARA C. Evaluation of selected indigenous pesticidal plant powders against stored maize and cowpeas insect pests. African Crop Science Conference Proceedings. 2011; 10: 189-193.

DASSANAYAKE MD \& FOSBERG FR. A Revised Handbook to the Flora in Ceylon. New Delhi, India: Amerind Publishing Co.Pvt.Ltd; 1985.

DEV S \& KOUL O. Insecticides of Natural Origin. Amsterdam, The Netherlands: Harwood Academic Publishers; 1997.

DHARMASENA CMD \& ABEYSIRIWARDENA DSDEZ. Effect of variety, grain moisture and packing material on weight and storage pests of rough rice during storage. Proceedings of the Annual Symposium of the Department of Agriculture. Anuradhapura, Sri Lanka; 2003.

FERNANDO S. Herbal food and medicines in Sri Lanka. New Delhi, India: Navrang Bookshellers and Publishers. 1982; 108.

FIELDS PG, XIE YS \& HOU X. Repellent effect of pea (Pisum sativum) fractions against stored product insects. Journal of Stored Products Research. 2001; 37: 359-370.

FOOD AND AGRICULTUREAL ORGANIZATION OF THE UNITED NATIONS. The use of spices and medicinal as bioactive protectants for grains. Rome, Italy: FAO; 1999.

HARSHA SN \& LATHA BV. In vitro antioxidant and in vitro anti inflammatory activity of Ruta graveolens methanol extract. Asian Journal of Pharmaceutical and Clinical Research. 2012; 5(1): 32-35.
HUMMELBRUNNER LA \& ISMAN MB. Acute, sublethal, antifeedant and synergistic effects of monoterpenoid essential oil compounds on the tobacco cutworm, Spodoptera litura (Lep. Noctuidae). Journal of Agricultural \& Food Chemistry. 2001; 49: 715-720.

JAYAWEERA DMA. Medicinal Plants (Indigenous \& Exotic) Used in Ceylon. Colombo, Sri Lanka: The National Science Council of Sri Lanka; 1982.

KIRTIKAR KR \& BASU BD. Indian Medicinal Plants. Debradun, India: International Book Distributiors; 1987.

KHOSHNOUD H, GHIYASI M, AMIRNIA R, FARD SS, TAJBAKHSH M, SALEHZADEH $\mathrm{H}$, et al. The potential of using insecticidal properties of medicinal plants against insect pests. Pakistan Journal of Biological Sciences. 2008; 11(10): 1380-1384.

MCDONALD LL, GUY RH \& SPEIRS RD. Preliminary evaluation of new candidate materials as toxicants, repellents and attractants against stored-product insects. Agricultural Research Service, US Department of Agriculture, Washington DC, Marketing Research Report No. 882. 1970.

MOHAN S \& FIELDS PG. A simple technique to assess compounds that are repellent or attractive to stored-product insects. Journal of Stored Products Research. 2002; 38: 23-31.

MOREIRA ACP, LIMA EO, SOUZA EL, DINGENEN MAU \& TRAJANO VT. Inhibitory effect of Cinnamomum zeylanicum Blume (Lauraceae) essential oil and beta-pinene on the growth of dematiaceous moulds. Brazilian Journal of Microbiology. 2007; 38: 3338.

NEIRO LS, OLIVERO-VERBEL J \& STASHENKO E. Repellent activity of essential oils: A review. Bioresource Technology. 2010; 101: 372-378. 
PALIPANE KP. Milling and quality improvement in rice. Proceedings of the Rice Symposium. Gannoruwa, Sri Lanka; 2000.

PALIPANE KP. Current storage practices and quality improvement of stored grains. Proceedings of the Seminar Organized by Sri Lanka Association for the Advancement of Science (SLASS) in Association with the University of Kelaniya and Food and Agriculture Organization. Kelaniya, Sri Lanka; 2001.

PARANAGAMA PA, ABEYSEKARA KHT, ABEYWICKRAMA K \& NUGALIYADDE L. Fungicidal and anti-aflatoxigenic effects of the essential oil of Cymbopogon citratus (DC.) Stapf. (lemongrass) against Aspergillus flavus Link. isolated from stored rice. Letters in Applied Microbiology. 2003; 37: 86-90.

POTENZA MR, JUNIOR JJ \& ALVES JN. Evaluation of contact activities of plant extracts against Sitophilus zeamais motschulsky (Coleoptera: Curculionidae). Proceedings of the $9^{\text {th }}$ International Working Conference on StoredProduct Protection. Sao Paulo, Brazil; 2006.

RAHMAN MA, TALEB MA \& BISWAS MM. Evaluation of botanical product as grain protectant against grain weevil, Sitophilus granarious (L.) on wheat. Asian Journal of Plant Sciences.2003; 2(6): 501-504.

RAHMAN SS, RAHMAN MM, KHAN MMR, BEGUM SA, ROY B \& SHAHED SMF. Ethanolic extract of melgota (Macaranga postulata) for repellency, insecticidal activity against rice weevil (Sitophilus oryzae). African Journal of Biotechnology. 2007; 6(4): 379-383.

RAJASHEKAR Y, BAKTHAVATSALAM N \& SHIVANANDAPPA T. Botanicals as grain protectants. Psyche. 2012; 2012: 13.

ROJHT H, KOSIR IJ \& TRDAN S. Chemical analysis of three herbal extracts and observationof their activity against adults of
Acanthoscelides obtectus and Leptinotarsa decemlineata using a video tracking system. Journal of Plant Diseases and Protection. 2012; 119(2): 59-67.

SINGH KK, TOMAR A \& RATHORE HS. Scope and limitations of neem products and other botanicals. Boca Raton, FI: Taylor \& Francis Group; 2010.

SUVANTHNI S, MIKUNTHAN G, THURAIRATNAM S \& PAKEERATHAN K. Evaluation of Withania somnifera extracts on a storage pest Rice weevil, Sitophilus oryzae Annuals of Biological Research. 2012; 3 (11): 5050-5053.

TALUKDER FA \& HOWSE PE. Deterrent and insecticidal effects of extracts of pithraj, Aphanamixis polystachya (Mcliaceae), against Tribolium castaneum in storage. Journal of Chemical Ecology. 1993;19: 2463-2471.

TAPONDJOU LA, ADLER C, BOUDA H \& FONTEM DA. Efficacy of powder and essential oil from Chenopodium ambrosioides leaves as post-harvest grain protectants against six-stored product beetles. Journal of Stored Products Research. 2002; 38: 395-402.

TRIPATHI P, DUBEY NK \& SHUKLA AK. Use of some essential oils as post-harvest botanical fungicides in the management of grey mould of grapes caused by Botrytis cinerea. World J Microbial Biotechnol. 2008; 24: 39-46.

WARIER PK, NAMBIAR VPK \& RAMANKUTTY C. Indian Medicinal Plants: A compendium of 500 species. Madras, India: Orient Longman; 1996.

WIJAYARATNE LKW, FERNANDO MD \& PALIPANE KB. Control of insect pests under ware house- conditions using smoke generated from partial combustion of rice (paddy) husk. Journal of the National Science Foundation of Sri Lanka. 2009; 37 (2): 125-134. 